\title{
Ruptured abdominal pregnancy at 35 weeks with live child - a case study at Kara university hospital (Togo)
}

\author{
Aboubakari AS, Ajavon DRD, Dossouvi T, Logbo-Akey KE, Dagbé M, Akpadza K \\ Correspondence: Dr. Dossouvi Tamegnon, Surgeon, Department of General surgery, \\ Teaching hospital of Kara, Togo; Email - dboris@ymail.com
}

Distributed under Attribution-NonCommercial-ShareAlike 4.0 International (CC BY-NC-SA 4.0)

\begin{abstract}
Abdominal pregnancy is a rare form of ectopic pregnancy. Advanced forms with live children at birth are exceptional. We report a case of abdominal pregnancy of 35 weeks with live child, referred and after emergency management. Maternal prognosis was good. The newborn, admitted to pediatric intensive care for breathing difficulties, died 8 days after birth.
\end{abstract}

Keywords: Abdominal pregnancy, live baby, ectopic placenta.

Ectopic pregnancy accounts for 1 to $2 \%$ of pregnancies and is located in more than $95 \%$ of cases in a fallopian tube ${ }^{1}$. Abdominal pregnancy, a particular form of ectopic pregnancy, is characterized by implantation of the fertilized egg into the peritoneal cavity ${ }^{2}$. This definition excludes tubal, ovarian and intraligamentary pregnancies ${ }^{3}$. Abdominal pregnancy occurs in $1.4 \%$ of ectopic pregnancies and its incidence varies from 1 case per 400 pregnancies to 1 case per 50000 pregnancies depending on the region. It is more common in developing countries, particularly in sub-Saharan Africa ${ }^{4}$.

Primary peritoneal implantation is rare. Secondary implantation is the most common 5. Pregnancy termination is usual because of trophoblastic invasion and frequent placental abruption ${ }^{4}$. Abdominal pregnancy is said to be early before 20 weeks of amenorrhea and late after 20 weeks of amenorrhea. Patient is always at high risk of maternal and fetal complications ${ }^{6}$. Late abdominal pregnancy with live child is extremely rare. Between 2008 and 2013, 38 cases were identified in the literature ${ }^{7}$. We report a case of abdominal pregnancy at 35 weeks of amenorrhea with live child, complicated by hemoperitoneum.

\section{Case report}

Two para patient, 28-year-old, with 3-year-old child, with no contraception, no pelvic surgery, no infertility or smoking history was received on November 12, 2017, during a mobile obstetric ultrasound session at the Baga peripheral care unit, for diffuse abdominal pain, asthenia and vertigo. She was on her first ultrasound examination for the current pregnancy. Ultrasound examination revealed an empty uterus with a live fetus intra-abdominal (fetal heart rate 184 beats per minute), biometrics corresponding to 33 weeks 4 daye of amenorrhea, and with intra-abdominal fluid effusion. The placenta was inserted into the posterior wall of the uterus. The pregnant woman was referred to Kara University Hospital the same day for treatment.

Received: $12^{\text {th }}$ September 2018. Accepted: $20^{\text {th }}$ October 2018.

Aboubakari AS, Ajavon DRD, Dossouvi T, Logbo-Akey KE, Dagbé M, Akpadza K. Ruptured abdominal pregnancy at 35 weeks with live child - a case study at Kara university hospital (Togo). The New Indian Journal of OBGYN. 2019; 5(2): 154-8 
Upon admission to Gynecology and Obstetrics department at Kara University Hospital, she presented with lipothymia with profuse sweat and cold extremities. Examination of the general condition had revealed cutanomucous pallor, arterial hypotension with BP of $80 / 50 \mathrm{~mm} \mathrm{Hg}$, peripheral pulse at 120 beats per minute and respiratory rate of 20 cycles per minute. Resuscitation measures were rapidly started with the establishment of two venous approaches and blood samples were collected for the determination of blood group, rhesus factor ( $\mathrm{Rh}$ group positive) and hemogram. Her hemoglobin level was $8 \mathrm{gm} / \mathrm{dl}$ and the coagulation profile was not feasible due to lack of equipment. Blood transfusion was started at the same time of rapid clinical evaluation. The date of her last period was back in March 19, 2017, corresponding to a pregnancy of 35 weeks of amenorrhea. She attended three prenatal consultations at the Peripheral Care Unit where she received $120 \mathrm{mg}$ ferrous fumarate and $0.4 \mathrm{mg}$ folic acid for the prevention of anemia and two doses of sulfadoxine-pyrimethamine for prevention malaria during pregnancy. From the fifth month of pregnancy, she complained of recurrent diffuse abdominopelvic pain, triggered or accentuated by active fetal movements, which persisted despite repeated doses of phloroglucinol (160 $\mathrm{mg}$ twice daily for 7 days) and paracetamol (1 g twice daily as needed). There was no history of trauma, digestive disorders, urinary disorders and genital hemorrhage.

On physical examination, the abdomen was large, painful as a whole on palpation on the sudden release of compression of the umbilicus. No contracted uterus was palpated. The fetus was in transverse position. The height of the uterus was measured at $28 \mathrm{~cm}$. Fetal heart sounds were counted at 180 beats per minute. At the percussion there was a dullness over the flanks. Speculum examination revealed a single cervix and absence of genital hemorrhage. With the vaginal touch combined with abdominal palpation, the cervix was posterior, closed and the fetal presentation was high and the posterior vaginal cul-de-sac was bulging and painful. The pregnant woman was quickly taken into the operating room for an exploratory laparotomy. Medial sub-umbilical laparotomy was performed under general anesthesia with orotracheal intubation. At the opening, the fetus was without an ovular sac, covered with blood (Figure 1). After extraction of the fetus by its podalic pole, we proceeded for the exploration of the abdominal cavity. There was a large hemoperitoneum with many dark red clots. We

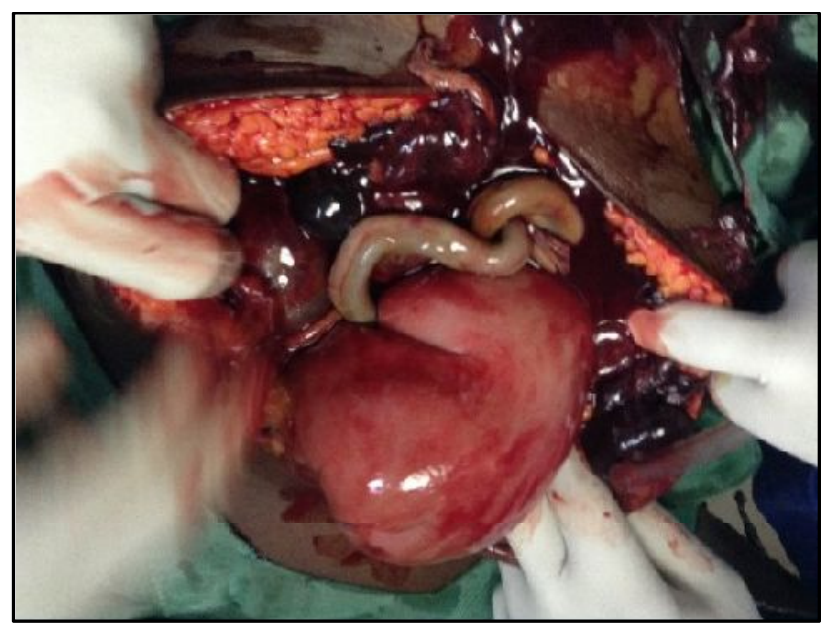

Figure 1: Fetus in the abdominal cavity, covered with blood

sucked 2 liters of blood and extracted $500 \mathrm{~g}$ of clots. The placental bed was very haemorrhagic (Figure 2).The placenta, partly detached, adhered to the posterior surface of the uterus, the left uterine appendages, and the omentum. Intestinal loops, mesentery, iliac vessels, and right uterine appendages were normal. There were no adhesions. Removal of the placenta was done associated

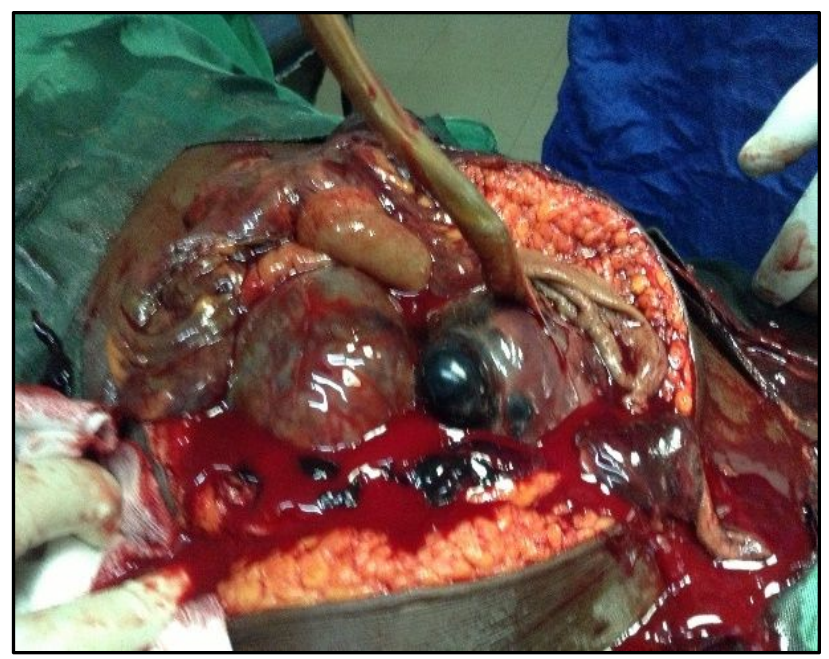

Figure 2: Hemorrhagic abdominal placental bed 
with left adnexectomy and partial omentectomy. Hemostasis was achieved. We finally performed the parietal closure after washing-aspiration without drainage of the peritoneal cavity, by fascial and cutaneous sutures. The surgical specimens have not been send for histopathological study because of limited financial resources. The newborn female, weighing $2100 \mathrm{~g}$, had an APGAR score of 6 in the first minute and 5 in the fifth minute. She had no abnormal external malformation and was admitted to a pediatric resuscitation unit for breathing difficulties. She was maintained on oxygen therapy and the neonatal death occurred on the eighth day. Postoperative maternal care consist mainly of transfusion of $1350 \mathrm{ml}$ of packed red blood cells, ceftriaxone antibiotics ( $1 \mathrm{~g}$ twice daily for 7 days) and paracetamol analgesic ( $1 \mathrm{~g}$ three times daily for 5 days). The follow-up was simple and the patient was discharged from the hospital after 7 days on levonorgestrel dermal implant. She was well one year after surgery and continued to use the contraceptive method.

\section{Discussion}

Abdominal pregnancy is the only ectopic pregnancy that can progress upto term ${ }^{8}$. Most abdominal pregnancies are secondary to tubal rupture or tuboabdominal abortion ${ }^{9}$. The frequency of abdominal pregnancy is higher in sub-Saharan Africa due to the high prevalence of sexually transmitted infections and subsequent tubal lesions ${ }^{10}$ and the low socio-economic level of the populations ${ }^{11}$. It varies from 2256 cases in Congo to 1 in 2941 cases in Nigeria ${ }^{12}$. The case that we report was late in diagnosis and fortuitous during a mobile session of ultrasound in a unit of peripheral care. The risk factors of abdominal pregnancy are multiparity, tubal pathology or surgery, pelvic endometriosis etc ${ }^{13}$. The patient in our study had no risk factors for ectopic pregnancy. The positive diagnosis of abdominal pregnancy is often intraoperative ${ }^{8}$. Preoperative diagnosis is often overlooked. It is often overlooked during prenatal consultations and despite the routine use of ultrasound ${ }^{14}$. The diagnosis of abdominal pregnancy before the sixth month of pregnancy is rare in developing countries where health centers are under-equipped; resulting in high perinatal mortality and high maternal morbidity (severe haemorrhage, bowel obstruction, infection) ${ }^{4}$. The clinical manifestations of abdominal pregnancy vary and depend on the seat and gestational age at diagnosis. Abdominal pregnancy may go unnoticed until advanced gestational age, during which most cases are diagnosed ${ }^{15}$. Abdominal pregnancy does not have specific clinical signs. The most commonly observed symptoms are recurrent abdominopelvic pain (100\% of cases) or painful active fetal movements ( $70 \%$ of cases). Physical examination is suggestive in the case of generalized abdominal defense, abnormal fetal presentation, palpation of the fetus and cervical deviation ${ }^{9,14}$. Signs of peritoneal irritation (vomiting, nausea, umbilical cry, generalized defense) and haemodynamic shock (paleness, tachycardia, cold sweats, low blood pressure) may indicate hemoperitoneum by placental abruption. Abdominal pregnancy manifesting itself as an abdominal emergency and a state of shock secondary to severe intra-abdominal hemorrhage, as in our study, is however unusual ${ }^{9}$.

Abdominal pregnancy can become complicated at any gestational age. Hemorrhagic complication is the most common. Patients, as in our study, are often in a state of hemorrhagic shock that reflects hemoperitoneum secondary to placental abruption ${ }^{16}$. Indeed the placenta can peel off at any time during pregnancy, unpredictably, and be the cause of a hemoperitoneum. It can also implant on any of the abdominal organs, but it often sits on or near the uterine wall. Its insertion on the uterus would maintain fetal development ${ }^{17}$. In our study, as in that of Mengistu et al, abdominal pregnancy was diagnosed preoperatively by ultrasound ${ }^{8}$. Abdominal ultrasound is the first-line paraclinical examination for diagnosis. It is suspected in cases of uterine vacuity, gestational sac not surrounded by myometrial structure and not separated from the maternal bladder by a myometrial structure ${ }^{5,14}$. Unfortunately, ultrasound is an operator-dependent examination and may miss the diagnosis. Magnetic resonance imaging is the alternative ${ }^{18}$. The presence and the abundance of the amniotic fluid, in the abdominal pregnancy, is one of the criteria of good fetal prognosis. Its presence would protect against fetal deformities ${ }^{4,}{ }^{19}$. Spontaneous rupture of amniochorial membranes, as in our study, is possible. According to D'cunha, free amniotic fluid in the peritoneal cavity promotes peritonitis ${ }^{20}$. Ultrasound allowed the diagnosis of abdominal pregnancy in our study. But it is not accessible to all pregnancy in our countries and especially in rural areas. The diagnosis of 
abdominal pregnancy in our study was made during a mobile session of obstetric ultrasound in rural areas. This was the first ultrasound examination for this multi-site pregnant woman, despite her antenatal care and recurrent abdominal pain.

Abdominal pregnancy, often diagnosed during complication stage, requiring urgent management. This management began in our study by the implementation of resuscitation measure. The treatment remains surgical. The therapeutic attitude depends on the gestational age, the site of placental implantation and the absence or presense of hemoperitoneum ${ }^{4,6,21}$. In our study, as in that of Matovelo et al, it consisted of an emergency exploratory laparotomy, under general anesthesia, through a medial umbilical incision ${ }^{22}$. On exploration, the uterus was in pelvis, the amniotic sac was broken, the fetus was free in the abdominal cavity with hemoperitoneum; the placenta was adhered to the omentum, uterine fundus and left uterine horn. Extraction of the newborn was followed by aspiration of the blood and removal of the placenta after resection of the affected horn, partial omentectomy, and ipsilateral adnexectomy ${ }^{22}$. Intraoperative blood transfusion is often necessary because the extraction of the placenta is at high risk of cataclysmic haemorrhage ${ }^{22}$.

The maternal and fetal prognosis is reserved in the abdominal pregnancy. Morbidity and maternal mortality are related to the severity of hemorrhage, intestinal obstruction, CIVD and placental excision ${ }^{15,21}$. Maternal mortality by abdominal pregnancy ranges from 0.5 to $18 \%$ of cases ${ }^{23,24}$. Perinatal morbidity varies from 40 to $95 \%$ but survival after 30 weeks reaches $80 \%$ due to scientific progress. Similarly, children are born with deformities and malformations in 21 to $90 \%$ of cases. Fetal mortality varies from 40 to $95 \%$ of cases and $21 \%$ of children are born with malformations or deformities ${ }^{24,25}$. Fetal morbidity is dominated by prematurity, hypotrophy and malformations.

\section{Conflict of interest: None. Disclaimer: Nil.}

\section{References}

1.Jurkovic D. Diagnosis and management of ectopic pregnancy. British Med J. 2011; 342: 3397.
2.Dubey S, Satodiya M, Garg P, Rani M. Primary

Abdominal Pregnancy: A Case Report. J Clin Diagnostic Research. 2016; 10(11): 4-6.

3.Laila A, Shiuly C, Mazhari SI. Diagnostic dilemma in abdominal pregnancy. A case report. J BCPS. 2009; 27: $177-9$.

4.Fouelifack FY, Fouogue JT, Fouedjio JH, Sando Z. Viable abdominal pregnancy: a case report in Yaoundé (Cameroon). Pan Afr Med J. 2014; 18: 181.

5.Onan MA, Turp AB, Saltik A, Akyurek N, Taskiran C, Himmetoglu O. Primary omental pregnancy: Case report. Human Reprod. 2005; 20 (3): 807-9.

6.Krishna D, Damyanti S. Advanced abdominal pregnancy: a diagnostic and management dilemma. J Gynecol Surg. 2007; 23: 69-72.

7.Masukume G. Live births resulting from advanced abdominal extrauterine pregnancy, a review of cases reported from 2008 to 2013. Webmed Central Obstet Gynaecol. 2014; 5(1): WMC004510.

8.Mengistu Z, Getachew A, Adefris M. Term abdominal pregnancy: a case report. J Med Case Rep. 2015; 9:168.

9.Nkusu Nunyalulendho D, Einterz EM. Advanced abdominal pregnancy: case report and review of 163 cases reported since 1946. Rural Remote Health. 2008; 8(4):1087.

10.Gabkika BM, Ignome T, Diarra D. Abdominal pregnancy with live fetus at term at the South N'djamena district hospital - A case study. Sudan J. Med Sciences. 2015;10(2):77-80.

11.Correa P, Diadhiou F, Lauroy J, Bah MD, Diab A, Guindo S. Evolution exceptionnelle de la grossesse abdominale. J Gynecol Obstet Biol Reprod. 2015; 8(3): $235-41$.

12.Sunday-Adeoye I, Twomey D, Egwuatu EV, Okonta PI. A 30-year review of advanced abdominal pregnancy at the Mater Misericordiae Hospital, Afikpo, southeastern Nigeria (1976-2006). Arch Gynecol Obstet. 2011; 283(1): 19-24.

13.Maas DA, Slabber CF. Diagnosis and treatment of advanced extra-uterine pregnancy. S Afr Med J. 1975; 49: 2007-10.

14.Dahab AA, Aburass R, Shawkat W, Babgi R, Essa O, Mujallid RH. Full-term extrauterine abdominal pregnancy: a case report. J Med Case Reports. 2011; 5: 531.

15.MolinaroTA, Barnhart KT. Ectopic Pregnancies in Unusual Locations. Semin Reprod Med. 2007; 25(2):123-13.

16.Kenfack B, Noubom M, Bongoe A, Tsatedem FA, Ngono M. Ectopic pregnancy in a semi-rural area in Africa: epidemiological, clinical and therapeutic aspects about a 
The New Indian Journal of OBGYN. 2019 (January-June); 5(2)

series of 74 cases treated at the District Hospital of Sangmelima in southern Cameroon. Pan African Med J. 2012; 13: 71 .

17.Dubinsky TJ, Guerra F, Gormaz G, Maklad N. Fetal survival in abdominal pregnancy: a re $\neg$ view of 11 cases. $\mathrm{J}$ Clin Ultrasound. 1996; 24: 513-17.

18.Mahi M, Boumdin H, Chaouir S, Salaheddine T, Attioui $\mathrm{D}$, Amil T, et al. Un nouveau cas de grossesse abdominale. Journal de Radiologie. 2002 ; 83(7-8) : 989-92.

19.Kangulu IB, Umba EKN, Cibuabua DK, Nzaji MK, Kayamba PKM. About a case of very prolonged abdominal pregnancy. The Pan African Medical Journal. 2013;16: 26.

20.D'Cunha AP, Maroo SV. Report on two cases of advanced abdominal pregnancy presenting as intestinal obstruction. East African Medical Journal. 1971; 48(3): 116-21.

21.Bertrand G. Imaging in the management of abdominal pregnancy: a case report and review of the literature. J Obstet Gynaecol Can. 2009; 31(1): 57-62.

22.Matovelo D, Ng'walida N. Hemoperitoneum in advanced abdominal pregnancy with a live baby: a case report. BMC Research Notes. 2014; 7:106.
23.Zhang J, Li F, Sheng Q. Full-term abdominal pregnancy: a case report and review of the literature. Gynecol Obstet Invest. 2008; 65(2):139-41.

24.Adesiyun AG, Audu AI. Term extrauterine pregnancy in a Nigerian mother: a complication of uterine dehiscence. Arch Gynecol Obstet. 2008; 279(1): 75-7.

25.Stevens CA. Malformations and deformations in abdominal pregnancy. Am J Med Genet. 1993; 47: 1189-95.

Aboubakari AS ${ }^{1}$, Ajavon DRD $^{2}$, Dossouvi $\mathbf{T}^{3}$, Logbo-
Akey KE${ }^{4}$, Dagbé $\mathbf{M}^{5}$, Akpadza $\mathbf{K}^{6}$
${ }^{1}$ Department of Gynecology and Obstetrics, Kara
University Hospital, Togo; ${ }^{2}$ Department of
Gynecology and Obstetrics, Kara University
Hospital, Togo; ${ }^{3}$ Department of Surgery, Kara
University Hospital, Togo; ${ }^{4}$ Department of
Gynecology and Obstetrics, Kara University
Hospital, Togo; ${ }^{5}$ Department of Radiology, Kara
University Hospital, Togo; ${ }^{6}$ Department of
Gynecology and Obstetrics, Sylvanus Olympio
University Hospital, Togo.

Aboubakari $\mathrm{AS}^{1}$, Ajavon DRD ${ }^{2}$, Dossouvi $\mathrm{T}^{3}$, LogboAkey $\mathrm{KE}^{4}$, Dagbé $\mathrm{M}^{5}$, Akpadza $\mathrm{K}^{6}$

${ }^{1}$ Department of Gynecology and Obstetrics, Kara

University Hospital, Togo; ${ }^{2}$ Department of Gynecology and Obstetrics, Kara University Hospital, Togo; ${ }^{3}$ Department of Surgery, Kara University Hospital, Togo; ${ }^{4}$ Department of Gynecology and Obstetrics, Kara University Hospital, Togo; ${ }^{5}$ Department of Radiology, Kara University Hospital, Togo; Department of University Hospital, Togo. 